\title{
INSTRUMENTOS DE POLÍTICA URBANA PARA VALORIZAÇÃO DO PATRIMÖNIO HISTÓRICO: OUTORGA ONEROSA E TRANSFERÊNCIA DO DIREITO DE CONSTRUIR
}

\author{
Janaína Rigo Santin* \\ Elizete Gonçalves Marangon**
}

\begin{abstract}
RESUMO
O artigo tem como objeto o Estatuto da Cidade (Lei n. 10257/2001), enfatizando dois instrumentos de política urbana previstos na Lei do Meio Ambiente Artificial para valorização e proteção do patrimönio histórico: a outorga onerosa e a transferência do direito de construir. Trata-se da possibilidade de, em caso de tombamento, o proprietário do imóvel transferir seu direito de construir a outro imóvel, edificando acima do coeficiente básico de construção daquela região, sem a necessidade de pagar ao Poder Público. A pesquisa evidencia a importância de uma gestão voltada aos interesses de sua população, capaz de preservar tanto a sua história quanto desenvolver alternativas susstentáveis de desenvolvimento para as futuras gerações, criando alternativas legais para que o proprietário de imóvel tombado não tenha apenas ônus com o tombamento, mas também bônus. Para tanto o artigo analisa a gestào democrática municipal, a fim de demonstrar que a qualidade de vida das pessoas que habitam o meio urbano, bem como a preservação de seus laços históricos e culturais, trata-se de um processo compartilhado entre poder público e cidadãos.
\end{abstract}

Palavras-chave: Cidadania. Estatuto da Cidade História. Poder local. Princípio da participação.

\section{CONSIDERAÇÕES INICIAIS: O ESTATUTO DA CIDADE}

O Estatuto da Cidade (Lei n. 10.257/2001), também denominado de Lei do Meio Ambiente Artificial, tem como objetivo formular diretrizes gerais de administração do ambiente urbano. Veio para regulamentar os artigos $182 \mathrm{e}$ 183 da Constituição Federal frente aos reclames de ordem pública, interesse social, bem estar dos cidadãos e equilíbrio ambiental, estabelecendo normas gerais para a política de desenvolvimento urbano.

Régis Fernandes de Oliveira, ao comentar os artigos 182 e 183 da Constituição Federal, ressalta que há uma remissão do texto constitucional à lei ordinária federal para a definição de diretrizes gerais para a política urbana; porém, "a especificidade, como não poderia deixar de ser, compete ao Município, atendendo a suas necessidades locais e decidindo de acordo com os superiores interesses da cidade". ${ }^{1}$ Dessa forma, o Estatuto da Cidade 
deixou a cargo de cada Município efetivar os seus dispositivos segundo as características locais, regulamentadas no Plano Diretor.

Mostra-se como instrumento jurídico hábil a proteger o meio ambiente artificial, indo ao encontro do artigo 225 da Constituição Federal de 1988:

\begin{abstract}
Art. 225 - Todos têm direito ao meio ambiente ecologicamente equilibrado, bem de uso comum do povo e essencial à sadia qualidade de vida, impondo-se ao Poder Público e à coletividade o dever de defendê-lo e preservá-lo para as presentes e futuras gerações.
\end{abstract}

As cidades neste século, marcadas pelo crescimento rápido e sem planejamento, expõem cada vez mais seus habitantes a condições subhumanas, criando uma situação de desequilíbrio, em detrimento da dignidade da pessoa humana. Celso Antonio Pacheco Fiorillo ${ }^{2}$ defende a aplicação do Estatuto da Cidade em face de territórios que não cumprem sua função social, lugares em que não há o adequado aproveitamento do solo urbano. Isso se dá a fim de que todos tenham acesso à cidade e aos recursos urbanísticos por ela oferecidos.

Forte em tais razões, do ponto de vista jurídico, o Estatuto da Cidade salvaguarda o meio ambiente urbano justo, equilibrado e sustentável, estabelecendo que toda a atividade econômica deve ter especial planejamento por parte do administrador público, observando-se os limites de sustentabilidade ambiental. E sendo assim, nada impede que se questione 0 ônus de viver em comunidade, cabendo a cada indivíduo a sua quota parte em participar do processo de planejamento urbano, e ao administrador público sua obrigação em utilizar os instrumentos urbanísticos, econômicos, tributários e financeiros previstos em lei para atendimento das finalidades públicas, devendo esforçar-se da melhor e mais justa maneira possível as receitas a sua disposição. ${ }^{3}$

Nesta feita, as diretrizes gerais e os instrumentos de política urbana previstos no Estatuto da Cidade formam um plexo de normas que permitem o racional aproveitamento do solo urbano, planificando a vida em comunidade, dando à propriedade sua função social, com o objetivo de melhoria da qualidade do meio ambiente urbano, em todas suas dimensões. ${ }^{4} \mathrm{E}$ dentre os novos instrumentos de política urbana descritos no Estatuto da Cidade, o presente artigo dá ênfase à outorga onerosa e à transferência do direito de construir, visando atingir, imediatamente, a função social da cidade e da propriedade urbana e, mediatamente, o princípio da dignidade da pessoa humana a seus habitantes.

O Estatuto da Cidade evidencia ainda a importância da gestão democrática municipal como um mecanismo implementador do princípio da dignidade da pessoa humana. Diante da constatação da situação de desequilíbrio vivenciada na grande maioria das cidades, em que grande parte dos habitantes permanece à margem da infra-estrutura e dos serviços públicos municipais (gerando conceitos como cidade formal - incluídos - e cidade informal - excluídos), a gestão democrática municipal mostra-se um importante 
instrumento nas mãos da cidadania a fim de reverter este estado de coisas, a partir de sua participação na aprovação coletiva dos projetos para a cidade. Pleiteia-se, com essa nova política urbana, o direito de cada cidadão em participar do planejamento a respeito do desenvolvimento da cidade, garantindo que elas sejam sustentáveis para esta e para as futuras gerações.

\section{A OUTORGA ONEROSA DO DIREITO DE CONSTRUIR}

Dentre as atribuições conferidas ao titular do direito real de propriedade estão a de usar, gozar e dispor de seu bem, bem como o direito de reavê-la daqueles que injustamente a possuam ou detenham (artigo 1.228 do Código Civil Brasileiro). Dessa forma, o direito de construir é corolário do direito real de propriedade, possibilitando ao titular do domínio erigir construção ou acessão conforme as suas conveniências. ${ }^{5}$

Já não há mais no direito de propriedade o caráter de direito absoluto; deverá, outrossim, cumprir uma função. Conforme dispõe o parágrafo $1^{\circ}$ do mesmo artigo, seu exercício se dará em consonância com as suas finalidades econômicas e sociais e de modo que sejam preservados, de conformidade com o estabelecido em lei especial, a flora, a fauna, as belezas naturais, o equilíbrio ecológico e o patrimônio histórico e artístico, bem como evitada a poluição do ar e das águas.

Assim, por mais que o direito tutele o interesse do proprietário do direito real de propriedade, quando há a violação do interesse público pelo descumprimento pelo titular do domínio das finalidades econômicas e sociais da propriedade urbana, no confronto entre interesse privado e público o ordenamento jurídico dará preferência ao interesse público.

Dessa forma, o direito de construir passa também a estar limitado por leis federais, estaduais e municipais, as quais definem a sua amplitude (coeficiente de aproveitamento do imóvel), sua destinação (comercial, residencial ou industrial), bem como a observância da legislação de vizinhança, urbanística e de direito ambiental. Evidencia-se aqui a necessidade de reconhecimento da dimensão de usufruir do imóvel da forma conveniente ao proprietário, respeitando-se, todavia, as limitações decorrentes de lei e, ainda, os direitos de vizinhança, aeração e iluminação, devendo preconizar a área edificável e o coeficiente máximo de aproveitamento do solo.

Cabe ao Município definir em seu âmbito territorial qual será o coeficiente de aproveitamento de seus imóveis. Divide-se a superfície do Município em áreas, delimitando em seu Plano Diretor os coeficientes mínimo, básico e máximo de aproveitamento dos terrenos. O coeficiente mínimo corresponde ao mínimo de área edificável exigida naquela região para que o imóvel cumpra sua função social (art. $5^{\circ}$, par. $1^{\circ}$ da Lei 10.257/2001). O coeficiente básico é o percentual de área que o proprietário pode construir sem pagar ao poder público. Já o coeficiente máximo define o máximo da capacidade de construção que aquela área suporta sem prejudicar a qualidade de vida de seus habitantes. 
Conforme parágrafo $1^{\circ}$ do artigo 28 do Estatuto da Cidade, "coeficiente de aproveitamento é a relação entre a área edificável e a área do terreno". Assim, faz-se um cálculo do percentual necessário de área para que se possa construir um prédio de " $x$ " área construída. A construção que for além do coeficiente básico e até o máximo será objeto da outorga onerosa do direito de construir. Quem definirá o limite máximo a serem atingido pelo coeficiente de aproveitamento será o Plano Diretor, "considerando a proporcionalidade entre a infra-estrutura existente e o aumento de densidade esperado em cada área" (artigo 28, parágrafo $3^{\circ}$ ). Trata-se aqui de uma medida de planejamento urbano, autorizando construções apenas quando for possível à cidade suportar, como um todo, os ônus daquele empreendimento.

Abre-se a possibilidade no parágrafo $2^{0}$ do artigo 28 do Estatuto da Cidade de o Plano Diretor "fixar coeficiente de aproveitamento básico único para toda a zona urbana ou diferenciado para áreas específicas dentro da zona urbana". Aqui a lei confere ao Poder Público municipal decidir se estipulará coeficientes de aproveitamento diferentes para, por exemplo, zonas residenciais, comerciais ou industriais, bem como o ensejo de intensificar a urbanização em algumas áreas ou, contrariamente, restringir o povoamento, ou ainda incrementar as atividades econômicas, etc.

Já a outorga onerosa do direito de construir (ou solo criado) é o exercício do direito de construir acima do limite do coeficiente de aproveitamento básico estabelecido pelo Plano Diretor municipal, mediante remuneração aos cofres públicos a ser prestada pelo beneficiário. Conforme dispõe o caput do artigo 28 do Estatuto da Cidade, será o Plano Diretor quem irá fixar "áreas nas quais o direito de construir poderá ser exercido acima do coeficiente de aproveitamento básico adotado, mediante contrapartida a ser prestada pelo beneficiário". ${ }^{6}$ Logo, a outorga onerosa do direito de construir é instrumento que amplia o direito de construir, possibilitando ao proprietário exercê-lo acima do coeficiente de aproveitamento básico adotado pelo Município naquela região.

Da mesma maneira, o artigo 29 do Estatuto da Cidade permite ao proprietário dar destinação diversa àquela fixada no Plano Diretor. Trata-se de uma permissão para alteração do uso do solo urbano mediante contraprestação a ser prestada pelo beneficiário, utilizada como maneira de o Poder Público arrecadar quantia em dinheiro com vistas efetivar os diferentes objetivos descritos nos incisos I a IX do artigo 26 do Estatuto da Cidade. ${ }^{7}$

Concretamente, 0 instrumento da outorga onerosa do direito de construir tem apresentando resultados positivos em alguns Municípios brasileiros que o aplicaram:

Em CURITIBA, figura da outorga onerosa aparece como Solo Criado - Lei Ordinária no 7.420 de 16 de março de 1990 - cujo objetivo é gerar recursos para financiar a habitação de interesse social. $O$ valor é pago para o Fundo Municipal de Habitação e empregado na compra de lotes ou na regularização fundiária. Segundo dados da Prefeitura, 720 empreendimentos habitacionais utilizaram-se do instrumento em 11 anos, arrecadando um total de $R \$ 18.036 .387,04$. A maioria dos imóveis onde foi aplicado o acréscimo de potencial 
construtivo localiza-se nas zonas residenciais 4, que são lindeiras ao sistema viário estrutural e às áreas no entorno do centro, embora ocorram também em outros pontos da cidade.

Em PORTO ALEGRE, a outorga onerosa funciona como forma de financiamento de obras viárias e de habitação de interesse social. Em 1975, essa legislação já aparecia em um decreto municipal. [...] O instrumento sofreu alterações em 1979 com a permissão de venda do potencial construtivo para terceiros. [...] Desde 1994, a outorga onerosa é feita a partir do estabelecimento de um limite construtivo máximo por quarteirão, na área de ocupação intensiva, que varia de 8 a $30 \%$. A possibilidade de compra de potencial construtivo adicional é ofertada em leilão ao conjunto de proprietários de um grupo de quarteirões. [...] Além destes mecanismos de leilão de potencial adicional, é possível comprar até $100 \mathrm{~m} 2$ como "ajuste de projeto "quando o projeto ultrapassa os parâmetros estabelecidos pelo zoneamento até este valor. [...] $O$ instrumento foi sendo progressivamente apropriado pelo mercado da construção civil, que vem utilizando cerca de $40.000 \mathrm{~m} 2$ por ano de potencial construtivo outorgado de forma onerosa valor que representa em média $9 \%$ do total construído a cada ano na cidade.

No DISTRITO FEDERAL ocorreu uma das únicas experiências de que temos notícias de legislação de outorga onerosa da Alteração de Uso que foi aprovada através da Lei n o 294 de 27 de junho de 2000. Inicialmente, o governo do Distrito Federal, através de decreto, permitia a outorga onerosa de uso, principalmente para a instalação de postos de gasolina. A Lei n o 1.170 da Outorga Onerosa do Direito de Construir foi aprovada em 24 de julho de 1996 e regulamentada pela Lei n o 19.436 de 16 de julho de 1998. Previa-se um desconto de $80 \%$ condicionado a toda alteração de gabarito ou adensamento. Este percentual genérico, inicialmente estipulado, deveria ser monitorado para que o instrumento tivesse um valor de planejamento e não simplesmente um valor tributário. Foi elaborado em 1998 o Projeto de Lei de Outorga Onerosa de Uso, mas este não chegou a ser encaminhado à Câmara Distrital. A Lei n o 294 de 27 de junho de 2000 da Outorga Onerosa da Alteração de Uso no DF, regula que os recursos auferidos irão, em 95\%,para o Fundo de Desenvolvimento Urbano do DF - FUNDURB [...]. As cidades satélites que não têm Planos Diretores podem, mesmo assim, ser objeto de aplicação das Outorgas, mas neste caso somente após a realização de Estudo Prévio de Viabilidade Técnica. Tem sido aplicado este instrumento nas cidades de Sobradinho, Taguatinga, Águas Claras, Planaltina, Gama e Ceilândia. ${ }^{8}$

A outorga onerosa do direito de construir criou vantagens e obrigações recíprocas para o ordenamento da cidade, alcançando a dignidade da pessoa humana, porque não se pode falar em urbanização justa quando não são observados os procedimentos específicos inerentes à condição humana. Logo, apresenta-se como importante ferramenta para resguardar os princípios fundamentais da Constituição Federal, protegendo juridicamente a pessoa humana das armadilhas criadas pela era da urbanização desenfreada. ${ }^{9}$ 


\title{
3 A TRANSFERÊNCIA DO DIREITO DE CONSTRUIR
}

Conforme visto no item anterior, o direito de construir deverá estar enquadrado a partir do coeficiente de aproveitamento básico do terreno estabelecido no Plano Diretor para aquele local. Acaso o proprietário queira construir acima do coeficiente de aproveitamento, será preciso uma contrapartida a favor do Poder Público, a qual poderá ser em dinheiro, obras ou serviços. Porém, este mesmo direito de construir poderá, a partir das novas disposições previstas no artigo 35 do Estatuto da Cidade, ser transferido para outro local ou negociado pelo seu proprietário. Esse procedimento dependerá de formalidade especial, que é a formalização de uma escritura pública. A simples existência dessa previsão concebe o direito de construir como instrumento jurídico-político, possibilitando tanto o seu exercício em outro território quanto a sua alienação onerosa.

Essa faculdade é concedida ao proprietário que doar ao Poder Público seu imóvel, nascendo de forma gradual, em certas circunstâncias. Da mesma maneira, a transferência do direito de construir beneficia proprietários de imóveis cujos poderes de uso e gozo são limitados pelo interesse coletivo de preservação do patrimônio histórico, ambiental, paisagístico, social ou cultural, bem como quando o imóvel é necessário para "implantação de equipamentos urbanos e comunitários", ou para "servir a programas de regularização fundiária, urbanização de áreas ocupadas por populações de baixa renda e habitação de interesse social" (artigo 35 do Estatuto da Cidade). Nas palavras de Marins:

\begin{abstract}
Proprietários de terrenos insertos em áreas de proteção ambiental, assim como os titulares do domínio de bens tombados, ao invés de se desinteressarem pela sorte desse precioso patrimônio natural ou cultural, ou promoverem desmatamentos, qualquer outro tipo de degradação ou destruição, poderão tirar proveito econômico do seu bem se o mantiverem com as características ambientais originárias, pois a preservação de áreas ou imóveis dessa natureza é uma das razões de ser do instituto da transferência do direito de construir. ${ }^{10}$
\end{abstract}

Logo, o Plano Diretor poderá autorizar o proprietário de imóvel urbano, tanto privado quanto público, a exercer em outro local ou alienar, mediante escritura pública, o direito de construir, por ocasião de o imóvel ser considerado necessário para preservação do patrimönio histórico, cultural ou paisagístico do município. Partindo dessa premissa, pode-se citar que tal direito pode ser imposto pelo Município ou exercido pelo proprietário que doar o seu imóvel, ou parte dele.

\footnotetext{
Este instrumento foi concebido de modo a permitir que os proprietários de imóveis a serem preservados fossem compensados pelo fato de que em seus imóveis o coeficiente ou densidade básicos estabelecidos para o território urbano não podem ser atingidos sob pena de comprometer o objetivo da preservação de imóveis de interesse histórico, paisagístico ou ambiental. No Estatuto está prevista também a hipótese de transferência para os casos de regularização fundiária e programas de habitação de interesse social. O proprietário de um imóvel sobre o qual incide um interesse público de preservação,seja sob o ponto de vista ambiental, ou sob os pontos de vista do patrimônio histórico, cultural, paisagístico e
} 
arquitetônico,ou ainda um imóvel que esteja ocupado por uma favela que se quer urbanizar,pode utilizar em outro imóvel,ou vender,a diferença entre a área construída do imóvel preservado e o total de área construída atribuída ao terreno pelo coeficiente de aproveitamento básico. [...]

Em CURITIBA a transferência de potencial construtivo - Lei $\mathrm{n}$ o 6.337/1982 e Lei n o 9.803/ 2000 - é um instrumento presente na Lei Orgânica do Município, sendo usada desde 1982 para preservação de patrimônio histórico. Seu uso foi ampliado em 2000, com a inserção de áreas verdes e de fundos de vale a serem preservados.A legislação determinou as zonas que podem receber transferências,com limites de área máxima a ser incorporada aos empreendimentos e os usos permitidos.[...] Muitas vezes a operação de restauro é feita em parceria,na qual o proprietário se associa a um empreendedor interessado em receber o potencial. [...] Estes dois instrumentos têm o objetivo de gerar recursos para o financiamento da restauração de imóveis públicos. [...]

A transferência de potencial construtivo para uma outra área é permitida apenas quando é inviável realizar a operação dentro de uma mesma área. $O$ instrumento já foi muito utilizado e gerou recursos para o município. [...] em uma arrecadação que soma $\mathrm{R} \$$ $7.124 .000,00 .^{11}$

Em síntese, nas palavras de Oliveira, a transferência do direito de construir poderá trazer forte impacto no mercado imobiliário, dando origem à propriedade virtual. Assim, o proprietário impedido de exercer seu direito no próprio imóvel, poderá construir em outro local, podendo os empreendedores imobiliários adquirir o direito de construir de proprietários que não possuam ou não queiram exercer o direito defluente de lei. ${ }^{12}$ Inaugura-se uma nova moeda de circulação no mercado e com valor econômico: o direito de construir.

\section{A GESTÃO DEMOCRÁTICA MUNICIPAL}

Dentre as diretrizes gerais de política urbana elencadas pelo Estatuto da Cidade em seu artigo 2oㅡ. inciso II, está a gestão democrática municipal. Trata-se de disponibilizar à população a participação na definição das tutelas jurídico-políticas municipais relativas ao aspecto orçamentário-financeiro e ao planejamento urbano. Essa matéria foi especificamente abordada em seu capítulo IV, intitulado "Da Gestão Democrática da Cidade"13. Mediante os dispositivos legais ali positivados, o Estatuto da Cidade instituiu instrumentos eficazes para induzir o Poder Público a agir com maior transparência, tendo em vista a inegável carência da participação dos cidadãos nas decisões políticas municipais. ${ }^{14}$

A gestão democrática das cidades deve tornar-se uma realidade, assegurando a "participação da população e de associações representativas dos vários segmentos da comunidade na formulação, execução e acompanhamento de planos, programas e projetos de desenvolvimento urbano" (art. 20 ${ }^{\circ}$, inc. II do Estatuto da Cidade), para se chegar a uma urbanização justa e equânime. As explicações apresentadas pelo Poder Público para a centralização das decisões não são aceitáveis, e se apóiam em 
alicerces antigos para justificar problemas novos. Por essa razão, urge se faça investimento de profundidade no Plano Diretor, e que ele seja uma formulação conjunta entre o Poder Público e os cidadãos, pois cabe a ele dirigir os destinos do Município, sendo obrigatório para as cidades com mais de vinte mil habitantes. Marcelo Lopes de Souza faz uma análise crítica acerca do tema da gestão democrática municipal:

O compromisso com a maior democratização possível do planejamento e da gestão de urbanos significa desmistificá-los, tirando-os de seu pedestal e entendendo-os como temas em que um tipo de saber técnico-científico deve desempenhar um papel, sim, mas cuja natureza, em última análise, é política, por dizer respeito a intervenções que mexem significativamente com a vida das pessoas. ${ }^{15}$

Logo, para o autor, mudar a cidade para inserir maior justiça social e igualdade é uma questão política, a ser construída democraticamente com a participação de todos os cidadãos.

\begin{abstract}
Mudar a cidade é uma tarefa coletiva. Esta frase, em qualquer circunstância uma obviedade, adquire maior conteúdo de verdade sob um ângulo autonomista, de vez que não se tratará, então de impor soluções de cima para baixo, mas de construí-las democraticamente. [...] O planejamento e a gestão urbanos, por tudo isso em face de tudo isso, são, no sentido mais profundo possível, políticos, ou um conhecimento técnico-científico mobilizado para alterar constelações de poder. ${ }^{16}$
\end{abstract}

O Estatuto diz que o governo não pode exercer o poder político sozinho, havendo a necessidade de um novo ponto de vista que seja inspirado na real aplicação da gestão democrática. Ou seja, para atingir os fins presentes no Estatuto da Cidade, que são a função social da cidade e da propriedade urbana, a gestão democrática mostra-se o melhor caminho.

Ainda que sejam respeitados os argumentos dos que preferem decidir acerca da cidade no interior de gabinetes, sem a participação coletiva, modernamente exige-se a adequada renovação dos instrumentos administrativos para que estejam em conformidade tanto com a Constituição Federal quanto com o Estatuto da Cidade. Portanto, tais restrições não podem perpetuar-se, sob pena de ilegalidade ou até mesmo inconstitucionalidade, devendo prevalecer os debates e as audiências públicas na definição das diretrizes jurídico-políticas do município, que são a essência da democracia. ${ }^{17}$

O ambiente urbano é o desafio aprovado pelo Estatuto da Cidade, na medida em que a política urbana deve avançar nos caminhos da gestão democrática, garantindo a participação popular nas decisões acerca dos ônus e dos benefícios do processo de urbanização. Enfatiza-se, portanto, a importância da gestão democrática municipal para a efetivação dos novos instrumentos de política urbana a serem inseridos no Plano Diretor dos Municípios, construindo cidades em que o processo de urbanização seja o resultado da aprovação coletiva. E aqui dá-se papel de destaque à outorga onerosa e à transferência do direito de construir, instrumentos prioritários para se atingir a função social da propriedade urbana e da cidade. 


\section{CONSIDERAÇÕES FINAIS: O ESTATUTO DA CIDADE E 0} PRINCÍPIO DA DIGNIDADE DA PESSOA HUMANA

Os valores que a sociedade estabelece como importantes devem prevalecer para a gestão democrática da cidade, passando obrigatoriamente pelos desdobramentos do princípio da dignidade humana, sem o qual não há justiça. Nesse sentido, qualquer discurso que não respeite as diretrizes fixadas pela Lei do Meio Ambiente Artificial parece muito distante de reduzir as desigualdades no âmbito habitacional. $O$ afastamento dos cidadãos das decisões acerca do ambiente urbano aumenta as possibilidades de que as verbas públicas sejam usadas para fins privados dos gestores públicos eleitos, prática contumaz nas gestões públicas municipais brasileiras em detrimento da prestação universal dos serviços públicos, o que fere as possibilidades de uma vida digna por grande parte da população.

A injusta distribuição dos benefícios decorrentes do processo de urbanização faz gerar a visão de uma cidade dividida em duas: a formal e a informal. Nas palavras de Isabel Oliveira:

\footnotetext{
$\mathrm{Na}$ primeira, moram, trabalham, circulam e se divertem os privilegiados grupos que têm acesso aos sofisticados investimentos públicos. A outra, denominada informal, está ocupada por população pobre que também trabalha, circula e se diverte na cidade, porém, mora em favelas, em loteamentos irregulares e loteamentos ilegais que cresceram e se expandiram sem a ação efetiva do poder público na dotação necessária dos serviços e equipamentos urbanos básicos. ${ }^{18}$
}

A inspiração dos direitos humanos sem a real aplicação na vida social e econômica não faz sentido, porque a pessoa humana precisa de condições para viver com dignidade, longe da falta de moradia e de saneamento básico, que atinge camadas mais frágeis da sociedade. Esse direito está contido na Carta magna, nos artigos 182, 183, artigo 50, inciso XXII e na Lei 10.257. A desigualdade econômica acentua o problema do inadequado ordenamento territorial, com ausente planejamento e controle do uso, do parcelamento e da ocupação do solo urbano. Portanto, toda decisão política deve ser tomada democraticamente, norteada pelo princípio da dignidade da pessoa humana, com vistas à efetiva garantia do caráter social da propriedade, a ser aproveitada e utilizada em serviço da coletividade. Por essas razões, Norberto Bobbio afirma que:

O problema que temos diante de nós não é filosófico, mas jurídico e,
num sentido mais amplo, político. Não se trata de saber quais e
quantos são estes direitos, qual é sua natureza e seu fundamento, se
são direitos naturais ou históricos, absolutos ou relativos, mas sim
qual é o modo mais seguro para garanti-los, para impedir que, apesar
das solenes declarações, eles sejam violados. ${ }^{19}$

Em prol de direitos de grande magnitude, como a vida e a dignidade da pessoa humana, é preciso todo um trabalho de efetivação que cabe aos 
representantes dos três poderes: o Executivo, ao formular as políticas públicas; - Legislativo, ao positivar a legislação regulamentar que dará o caráter de efetividade e concretude àqueles direitos; e o Judiciário, ao julgar sempre respeitando os princípios fundamentais do ordenamento jurídico. Nesse sentido, aduz Norberto Bobbio:

O problema do fundamento de um direito apresenta-se diferentemente conforme se trate de buscar o fundamento de um "direito que se tem" ou de um "direito que se gostaria de ter". No primeiro caso, investigo no ordenamento jurídico positivo, do qual faço parte como titular de direitos e de deveres, se há uma norma válida que o reconheça e qual é essa norma; no segundo caso, tentarei buscar boas razões para defender a legitimidade do direito em questão e para convencer o maior número possível de pessoas (sobretudo as que detêm o poder direto ou indireto de produzir normas válidas naquele ordenamento) a reconhecê-lo. ${ }^{20}$

Em sua mais ampla acepção, a dignidade humana é, ou devia ser, a razão da própria existência do Estado. Diante disso, o desrespeito à história e à cultura dos cidadãos, bem como a ilegal exposição do indivíduo ao meio ambiente desequilibrado constitui flagrante desrespeito ao princípio da dignidade da pessoa humana tanto desta quanto das futuras gerações. Nesse contexto, conceituar dignidade da pessoa humana é tarefa árdua, já que no passado não muito distante não se falava em dignidade dos escravos e outros trabalhadores. Veja-se a opinião de Canotilho:

Perante as experiências históricas da aniquilação do ser humano (inquisição, escravatura, nazismo, stalinismo, polpotismo, genocídios étnicos) a dignidade da pessoa humana como base da República significa, sem transcendências ou metafísica, o reconhecimento do 'homo noumenon', ou seja, do indivíduo como limite e fundamento do domínio político da República. Neste sentido, a República é uma organização política que serve ao homem, não é o homem que serve os aparelhos político-organizatórios. ${ }^{21}$

E assim sendo, necessário se faz que os agentes políticos busquem a gestão democrática, compreendendo o direito do cidadão em participar nas decisões acerca do ambiente urbano, bem como seu direito à história e à cultura. Somente com o processo co-gestionado de formulação das tutelas jurídico-políticas municipais é que será possível uma discussão honesta e responsável sobre o processo de urbanização. Apontado o Estatuto da Cidade num momento marcado pela preocupação com o ambiente urbano, torna-se, mais do nunca, oportuna a sua aplicação não só nos municípios em que a lei o faz obrigatório, mas em todas as cidades, visto que o cumprimento da função social da propriedade previsto no artigo 5 da Magna Carta, bem como artigos 182 e 183 da Constituição destinam-se a todos municípios brasileiros, sem exceção.

Trata-se de uma via de mão-dupla. De um lado, é fundamental que o Poder Público mostre-se vinculado às proposições estabelecidas no Estatuto da Cidade, devendo ser repudiados comportamentos que visam simplesmente ignorar dispositivos positivados, como os que dizem respeito à gestão 
democrática municipal, bem como aos instrumentos de política urbana da outorga onerosa e da transferência do direito de construir, previstos no Estatuto da Cidade. De nada adianta o ordenamento jurídico proclamar a necessidade de proteção do patrimônio histórico, cultural, paisagístico, artístico e urbano, se não forem adotados mecanismos efetivos para concretizar esta proteção. $\mathrm{E}$ neste escopo foram positivados a outorga e a transferência do direito de construir. Porém, é necessária sua positivação e regulamentação em âmbito municipal, para que os proprietários de imóveis tombados possam, mesmo com a limitação de sua propriedade, usufruir do benefício de poder transferir 0 potencial de construção daquele terreno (solo criado) para outro imóvel.

E, de outro lado, é imprescindível a atuação da população no sentido de exigir a efetividade das normas legais, mediante postulação perante o Poder Judiciário. Logo, acompanhando o entendimento de Oliveira, ${ }^{22}$ se a questão não restar resolvida, poderão os agentes públicos depararem-se com uma ação civil pública, a qual destina-se à apuração e sanção de agentes públicos que causarem danos ao meio ambiente, ao consumidor, a bens e direitos de valor artístico, estético, histórico, turístico e paisagístico. Nessa linha de pensamento, entende-se que a ação civil pública pode ocorrer em decorrência dos danos causados a tais valores, sendo cabível ação cautelar para defesa da ordem urbanística, a fim de se alcançar a harmonização dos valores em jogo, reconduzindo ao princípio fundamental da dignidade da pessoa humana.

\section{INSTRUMENTS OF URBAN POLICY FOR THE APPRECIATION OF HISTORICAL HERITAGE: ONEROUS GRANT AND THE TRANSFER OF RIGHT TO BUILD}

\section{ABSTRACT}

This article has as an object the City Statute (Law No 10257/2001), emphasizing two instruments of urban policy laid down in the Law of Artificial Environment: the onerous grant and the transfer of right to build. This means the possibility of, in the case of protected buildings, transferring the right to build to another building, by the owner of the property, being able to build above the basic building coefficient of the region, without having to pay the Public Power. The study highlights the importance of management directed to the interests of the population, and capable of preserving history as well as creating sustainable development alternatives for future generations, fostering legitimate alternatives for the owners of protected buildings not to end up with only the onerous part of the protection, but also with the bonus one. Thus the article analyzes the democratic municipal administration, in order to demonstrate that the quality of life of people who live in urban areas, as well as the preservation of their historical and cultural ties, is a shared process between public authorities and citizens. 


\author{
Keywords: City Statute. Citizenship. History. Local Power. Participative \\ Principle.
}

\title{
NOTAS
}

Doutora em Direito pela UFPR, Mestre em Direito pela UFSC, Advogada, Coordenadora de Pesquisa e Professora da Faculdade de Direito e do Mestrado em História da Universidade de Passo Fundo. E-mail: janainars@upf.br

* Advogada. Mestranda em História, área de concentração em História Regional, linha de pesquisa "Política e Cultura", na Universidade de Passo Fundo/RS. E-mail: elizetemarangon@yahoo.com.br.

1 OLIVEIRA, Régis Fernandes de. Comentários ao Estatuto da Cidade. São Paulo: Editora Revista dos Tribunais: 2002, p. 13.

2 FIORILLO, Celso Antonio Pacheco. Estatuto da Cidade Comentado: lei 10.257/2001: lei do meio ambiente artificial. São Paulo: Editora Revista dos Tribunais: 2002, p.40-42.

3 FIORILLO, Celso Antonio Pacheco. Estatuto da Cidade Comentado: lei 10.257/2001: lei do meio ambiente artificial. São Paulo: Editora Revista dos Tribunais: 2002. p.49-57.

4 OLIVEIRA, Régis Fernandes de. Comentários ao Estatuto da Cidade. São Paulo: Editora Revista dos Tribunais: 2002, p. 21-28.

5 Ressalta-se que houve uma alteração nos últimos anos no direito de construir, que é a possibilidade de ser destacado do direito de propriedade, coabitando no mesmo imóvel dois direitos reais: superfície e propriedade, os quais poderão estar concentrados em titulares referentes.

6 Ressalta-se que esta contrapartida, nas palavras de ROLNIK, "podem se dar sob a forma de obras, terrenos ou recursos monetários. Para que a transferência do potencial adicional ocorra,são estabelecidos 'estoques de área adicional' (quantidades totais de metros quadrados a serem vendidos)." ROLNIK, op. cit., p. 74-75.

7 São eles: regularização fundiária, execução de programas e projetos habitacionais de interesse social, constituição de reserva fundiária, ordenamento e direcionamento da expansão urbana, implantação de equipamentos urbanos e comunitários, criação de espaços públicos de lazer e áreas verdes, criação de unidades de conservação ou proteção de outras áreas de interesse ambiental, proteção de áreas de interesse histórico, cultural ou paisagístico.

8 ROLNIK, Raquel (Coord); SAULE JÚNIOR, Nelson (Coord). Estatuto da cidade: guia para implementação pelos municípios e cidadãos: Lei oํ 10.257, de 10 de julho de 2001 que estabelece diretrizes gerais da política urbana. 2. ed. Brasília: Câmara dos Deputados, Coordenação de Publicações, 2002, p.73-74.

9 FIORILLO, Celso Antonio Pacheco. Estatuto da Cidade Comentado: lei 10.257/2001: lei do meio ambiente artificial. São Paulo: Editora Revista dos Tribunais: 2002. p.65-68.

10 MARINS, Vinicius. O Estatuto da Cidade e a constitucionalização do Direito Urbanístico. Jus navigandi, Teresina, a. 8, n. 223, fev. 2004. Disponível em: http://www1.jus.com.br/doutrina/texto.asp?id=4806. Acesso em: 20 ago. 2004.

11 ROLNIK, Raquel (Coord); SAULE JÚNIOR, Nelson (Coord). Estatuto da cidade: guia para implementação pelos municípios e cidadãos: Lei no 10.257, de 10 de julho de 2001 que estabelece diretrizes gerais da política urbana. 2. ed. Brasília: Câmara dos Deputados, Coordenação de Publicações, 2002, p.76-79.

12 OLIVEIRA, Régis Fernandes de. Comentários ao Estatuto da Cidade. São Paulo: Editora Revista dos Tribunais: 2002, p. 93-98.

13 Art. 43.- Para garantir a gestão democrática da cidade, deverão ser utilizados, entre outros, os seguintes instrumentos: I- órgãos colegiados de política urbana, nos níveis nacional, estadual e municipal; II- debates, audiências e consultas públicas; III- conferências sobre assuntos de interesse urbano, nos níveis nacional, estadual e municipal; IV- iniciativa popular de projeto de lei e de planos, programas e projetos de desenvolvimento urbano.

Art. 44.- No âmbito municipal, a gestão orçamentária participativa de que trata a alínea $f$ do inciso III do art. 4. desta Lei incluirá a realização de debates, audiências e consultas públicas sobre as propostas do plano plurianual, da lei de diretrizes orçamentárias e do orçamento anual, como condição obrigatória para sua aprovação na Câmara Municipal. 
Art. 45.- Os organismos gestores das regiões metropolitanas e aglomerações urbanas incluirão obrigatória e significativa participação da população e de associações representativas dos vários segmentos da comunidade, de modo a garantir o controle direto de suas atividades e o pleno exercício da cidadania.

14 Para um maior aprofundamento do tema ver SANTIN, Janaína Rigo. O Estatuto da Cidade e a Gestão Democrática Municipal. Revista Interesse Público, ano 5, n. 21, set./out. 2003, Porto Alegre: Notadez, p. 220-229.

15 SOUZA, Marcelo Lopes de. Mudar a cidade: uma introdução crítica ao planejamento e à gestão urbanos. 2. ed. Rio de Janeiro: Bertrand Brasil, 2003. p. 313-431.

16 SOUZA, Marcelo Lopes de. Mudar a cidade: uma introdução crítica ao planejamento e à gestão urbanos. 2. ed. Rio de Janeiro: Bertrand Brasil, 2003. p. 518-532.

17 OLIVEIRA, Régis Fernandes de. Comentários ao Estatuto da Cidade. São Paulo: Editora Revista dos Tribunais: 2002, p. 102-112.

18 OLIVEIRA, Isabel Cristina Eiras de. Estatuto da Cidade: para compreender. Rio de Janeiro: IBAM/DUMA, 2001. p. 15-16.

19 BOBBIO, Norberto. A Era dos Direitos, 1992, p. 25.

20 BOBBIO, Norberto. A era dos direitos, 1992, p. 15.

21 CANOTILHO, Jose Joaquim Gomes. Direito Constitucional, 1999, p. 221.

22 OLIVEIRA, Régis Fernandes de. Comentários ao Estatuto da Cidade. São Paulo: Editora Revista dos Tribunais: 2002, p. 125.

\section{REFERÊNCIAS}

BRASIL. Lei no 10.257, de 10 de julho de 2001: regulamenta os arts. 182 e 183 daConstituição Federal, estabelece diretrizes gerais da política urbana e dá outras providências. Lex: ACQUAVIVA, Marcus Cláudio. Vademecum universitário de direito. 5. ed. rev. ampl. São Paulo: Jurídica Brasileira, 2002

BOBBIO, Norberto. A era dos direitos. Tradução de Carlos Nelson Coutinho. Rio de Janeiro: Campus, 1992.

CANOTILHO, José Joaquim Gomes. Direito constitucional. 3. ed. Coimbra: Livraria Almedina, 1999.

DI SARNO, Daniela Campos Libório. Elementos de direito urbanístico. São Paulo: Manole, 2004.

FIORILLO, Celso Antonio Pacheco. Estatuto da Cidade Comentado: lei 10.257/2001: lei do meio ambiente artificial. São Paulo: Editora Revista dos Tribunais: 2002.

MARINS, Vinicius. O Estatuto da Cidade e a constitucionalização do Direito Urbanístico. Jus navigandi, Teresina, a. 8, n. 223, fev. 2004. Disponível em: http://www1.jus.com.br/doutrina/texto.asp?id=4806. Acesso em: 20 ago. 2004.

OLIVEIRA, Isabel Cristina eiras de. Estatuto da Cidade: para compreender... Rio de Janeiro: IBAM/DUMA, 2001.

OLIVEIRA, Regis Fernandes de. Comentários ao estatuto da cidade. São Paulo: Editora Revista dos Tribunais, 2002.

PINHO, Evangelina; BRUNO FILHO, Fernando Guilherme; MATTOS, Liana Portilho (Org). Estatuto da cidade. Belo Horizonte: Mandamentos, 2002.

ROLNIK, Raquel (Coord); SAULE JÚNIOR, Nelson (Coord). Estatuto da cidade: guia para implementação pelos municípios e cidadãos: Lei no 10.257, de 10 de julho de 2001 que estabelece diretrizes gerais da política urbana. 2. ed. Brasília: Câmara dos Deputados, Coordenação de Publicações, 2002. 
SOUZA, Marcelo Lopes de. Mudar a cidade: uma introdução crítica ao planejamento e à gestão urbanos. 2. ed. Rio de Janeiro: Bertrand Brasil, 2003.

Recebido para publicação 25/04/2008

Aceito para publicação 23/12/2008 